\title{
BMJ Open Emergency nurse disaster preparedness during mass gatherings: a cross-sectional survey of emergency nurses' perceptions in hospitals in Mecca, Saudi Arabia
}

\author{
Fuad Alzahrani, ${ }^{1}$ Yiannis Kyratsis ${ }^{2}$
}

To cite: Alzahrani F, Kyratsis Y. Emergency nurse disaster preparedness during mass gatherings: a cross-sectional survey of emergency nurses' perceptions in hospitals in Mecca, Saudi Arabia. BMJ Open 2017;7:e013563. doi:10.1136/bmjopen-2016013563

- Prepublication history for this paper is available online. To view these files please visit the journal online (http://dx.doi.org/10.1136/ bmjopen-2016-013563).

Received 20 July 2016 Revised 21 November 2016 Accepted 20 December 2016

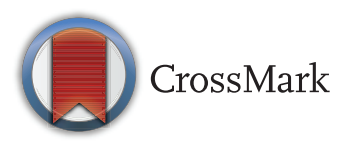

${ }^{1}$ Ministry of Health Saudi Arabia, King Fisal Hospital, Mecca, Saudi Arabia

${ }^{2}$ School of Health Sciences, City, University of London, London, UK

Correspondence to Fuad Alzahrani; alnbhan_fm@hotmail.com

\section{ABSTRACT}

Objectives: To assess hospital emergency nurses' self-reported knowledge, role awareness and skills in disaster response with respect to the Hajj mass gathering in Mecca.

Design: Cross-sectional online survey with primary data collection and non-probabilistic purposive sample conducted in late 2014.

Setting: All 4 public hospitals in Mecca, Saudi Arabia. Participants: 106 registered nurses in hospital emergency departments.

Main outcome measure: Awareness, knowledge, skills and perceptions of emergency nurses in Mecca with regard to mass gathering disaster preparedness.

Results: Although emergency nurses' clinical role awareness in disaster response was reported to be high, nurses reported limited knowledge and awareness of the wider emergency and disaster preparedness plans, including key elements of their hospital strategies for managing a mass gathering disaster. Over half of the emergency nurses in Mecca's public hospitals had not thoroughly read the plan, and almost 1 in 10 were not even aware of its existence. Emergency nurses reported seeing their main role as providing timely general clinical assessment and care; however, fewer emergency nurses saw their role as providing surveillance, prevention, leadership or psychological care in a mass gathering disaster, despite all these broader roles being described in the hospitals' emergency disaster response plans.

Emergency nurses' responses to topics where there are often misconceptions on appropriate disaster management indicated a significant knowledge deficit with only 1 in 3 nurses at best or 1 in 6 at worst giving correct answers. Respondents identified 3 key training initiatives as opportunities to further develop their professional skills in this area: (1) hospital education sessions, (2) the Emergency Management Saudi Course, (3) bespoke short courses in disaster management.

Conclusions: Recommendations are suggested to help enhance clinical and educational efforts in disaster preparedness.

\section{Strengths and limitations of this study}

- This is the first empirical study on the role of emergency nurses in mass gathering disaster preparedness in Saudi Arabia and the city of Mecca.

- The study provides valuable new information on the perceived preparedness of emergency nurses during the Hajj mass gathering against role standards as stated in the emergency plans of local hospitals.

- The study identifies specific health education and training programmes deemed appropriate and relevant by the emergency nurses.

- Limitations of this study include its crosssectional design, the relatively small and nonrandom sample, and the use of self-reported data.

\section{INTRODUCTION \\ Background}

Despite the central role of front-line nursing staff in hospital emergency departments (EDs) in responding to disasters, little is known about the knowledge and skill required by this group of health professionals to effectively carry out this important clinical role. In particular, there is a paucity of studies that directly measure aspects of disaster preparedness for emergency nurses (ENs) in the context of mass gatherings (MGs) ${ }^{1-3}$ Furthermore, there is an absence of studies on assessing ENs' perceived knowledge and role awareness in disaster response in Saudi Arabia, a country which hosts annually one of the world's largest MGs.

The WHO defines disaster as "an occurrence disrupting the normal conditions of existence and causing a level of suffering that exceeds the capacity of adjustment of the affected community." ${ }^{4}$ In addition, Kaji et $a \tilde{l}$ defined disaster as "a natural or 
man-made event that results in an imbalance between the supply and demand for resources." MGs are variously described in the literature with no widely agreed definition. Most researchers agree that MGs are events attended by a large number of people (ie, over 1000) at a specific location, for a defined period of time. ${ }^{6} 7$ Hammad $e t a l^{1}$ defined MGs as "events attended by a sufficient number of people to the level that strains the planning and response resources of the host where it is being held." In addition to straining the planning and response resources of the host country, MGs also pose special risks for attendees. Common risks include injuries and accidents, stampedes, spread of infectious diseases, and terrorism among others. ${ }^{7}$ The risk of a catastrophic incident occurring during MGs also presents particular challenges in the prevention, harm minimisation and emergency response of healthcare facilities. The distinctive features of MGs that can affect public health and safety services include their wide geographical spread, large levels of attendance, their duration and the security concerns that they present. For healthcare services, the main objective during MGs is to prevent or minimise the risk of injuries or illnesses and maximise the safety of participants. ${ }^{1} 89$

In the case of an emergency arising from any of the above risks, there will be a strain in the local healthcare facilities. Therefore, the nurses at EDs in hospitals should be adequately trained and prepared for such eventualities to provide for an effective response and help in reducing the number of potential fatalities. ${ }^{10}$ In particular, nurses working in EDs must have the essential knowledge, skills and experience to efficiently manage emergencies and cope with often chaotic circumstances accompanying a disaster.

A nascent body of literature informed by empirical work in emergency nursing disaster preparedness has started emerging, in particular in the context of MGs. In a mixed-methods study, Hammad et al reported on the knowledge and perceptions of ENs in South Australia on their role in disaster preparedness. Alexander ${ }^{11}$ explored the beliefs in common myths held by Massachusetts University students and three groups of trainee emergency workers in Italy. The research revealed that the participants held various misconceptions regarding disaster management. Magnaye $e t a l^{2}$ sought to determine the opinions held by ENs in the Philippines with regard to their role in disaster management. The research also examined their preparedness and levels of their skills in response to disasters.

Studies in this area suggest that a number of factors influence the ability of hospital nurses to respond to a disaster, particularly during MGs. Disaster education and training is a key element. ${ }^{12}$ Drills and exercises, as well as military training and postgraduate taught studies focusing on disaster response, constitute important aspects of education and training efforts. Nonetheless, there is less agreement in the literature regarding the content and the mode of delivery of such education programmes. In addition, the relevance of existing programmes to nursing professionals in EDs is questioned. ${ }^{5} 1013$

A second important factor influencing the effectiveness of ENs' response, particularly in the context of MGs, is their level of knowledge and awareness of the appropriate course of action. ${ }^{11}{ }^{14}$ Welzel $e t a l^{15}$ argue for the necessity of early communication of relevant information to ENs, which provides them with the opportunity to simulate their response, thus increasing their response capability.

Prior disaster management experience constitutes a third key factor in relation to ENs' preparedness in MG disasters. ${ }^{16}$ Welzel et $a l^{15}$ argue that experience can be gained by nurses coming from societies where disasters are uncommon by volunteering to practise in societies more prone to disasters; 'hands on' education and field training in this context can support ENs gaining valuable experience in disaster preparedness. ${ }^{1} 7917$ Finally, there is a reported need for collaboration and communication between the different professionals involved in the provision of care in EDs, including nurses, physicians, the management team and support staff. ${ }^{18}$

\section{Study objectives}

This study aims to contribute to our understanding of emergency nursing and disaster response preparedness in MGs. This study was designed to specifically assess the self-reported knowledge and disaster preparedness in relation to the annual Hajj pilgrimage of registered nurses currently working in the EDs of all public hospitals in Mecca. Hajj refers to the Muslim pilgrimage to Mecca in Saudi Arabia, performed annually by more than two million people originating from more than 140 countries globally. ${ }^{10} 1920$ The Hajj constitutes the largest annual MG in the world. ${ }^{18}$

The study had three key objectives:

1. To assess the level of awareness and self-reported knowledge in disaster response of the ENs working in public hospitals in Mecca.

2. To assess the current roles and skills in disaster preparedness during the Hajj MG as reported by the ENs included in our study, in particular against existing standards and plans in their hospitals.

3. To identify the type of training programmes and education deemed appropriate and relevant by the ENs studied.

\section{METHODS}

\section{Study design}

A cross-sectional online survey was selected as the most appropriate research design for the purpose of the study. ${ }^{21}$ A self-administered questionnaire was completed by eligible participants, including a combination of structured and open-ended questions. A survey questionnaire enables researchers to collect a large amount of data over a short time period, at low cost. Online survey administration provides convenience for busy professionals, such as 
nurses, to complete the questionnaire in their own time. Although the researcher being absent reduces control, it increases anonymity for participants, encouraging them to give more honest responses.

\section{Study site}

The setting for this study included all four public hospitals in Mecca, Saudi Arabia. Mecca was purposefully selected as the Hajj MG is held there annually, thereby increasing the potential risk for a disaster to occur in that locality. ${ }^{11} 121416$ We used non-probability purposive sampling. ${ }^{22}$ The target study population consisted of all registered nurses working in the EDs of all four public hospitals in Mecca $(\mathrm{N}=350)$.

\section{Study population}

Registered ENs in Saudi Arabia can be: (1) nursing technicians, who have a high diploma in nursing, (2) nursing specialists, who have bachelor's degrees in nursing or (3) nurses' aides, who have attended a 1 year course in nursing. ENs participating in the study were primarily either nursing technicians or specialists $(90 \%$ or $76 / 84$ of those who provided a response about their current clinical position). Participation in this study was voluntary and $106 \mathrm{ENs}$ returned completed questionnaires (30\% response rate).

\section{Outline of responsibilities of the EN role}

Registered ENs work in critical care emergency facilities as members of a clinical team with physicians, other nurses and allied health professionals to provide care, monitor health conditions, plan long-term care needs, administer medicine, use medical equipment, perform minor medical operations, and advise patients and their families on illness, care and follow-on care after a hospital stay. The emergency preparedness plans during the Hajj for the four hospitals in Mecca state that the role of all types of ENs includes the following five key clinical tasks: (1) provision of general assessment and care for patients, (2) triage of incoming patients, (3) performing resuscitation if needed, (4) demonstrating clinical leadership, and (5) providing psychological care to patients. These key clinical tasks have been assessed in our questionnaire.

\section{Study instrument}

The instrument we used to gather primary data for this study was an online self-administered questionnaire. The questionnaire included both structured and open-ended questions to collect standardised and spontaneous responses, respectively, and to allow respondents to provide more in-depth information, where appropriate. ${ }^{22}$ The questionnaire was designed and hosted on the 'Survey Monkey' website.

The development of the questionnaire's content was informed by similar studies. ${ }^{1} 211$ The questionnaire used in the current study borrowed extensively from the questions posed by the researchers in the studies enumerated above. The content was further adapted to include key clinical tasks described in the hospital emergency preparedness plans as advised by local experts during the pilot study. Consequently, the tool analysed the self-reported knowledge, skills and perceptions of ENs in Mecca with regard to disaster preparedness, including EN's awareness of the standards for their roles as outlined in the Major Incident Plans of the four hospitals in Mecca.

In this study, the questionnaire included 18 questions, which were divided into five sections. (1) Knowledge and awareness in relation to disaster preparedness: this section of the questionnaire addressed this aspect of the study by contextualising disaster response in the hospital setting in Mecca. The responses of the participants were measured in a five-point Likert scale ( 1 for strongly agree and 5 for strongly disagree). (2) Roles of nurses in disasters: this section comprised 12 items, which were measured in a 5-point Likert scale and focused on the roles of nurses in providing care, psychological assistance and triage, also as delineated in local hospital emergency and disaster preparedness plans (ie, the Major Incident Plans). (3) Education and training: four items were designed to identify types of disaster education and training available and perceived as relevant by the ENs in hospitals in Mecca. (4) Previous experience on disaster response: nine items explored respondents' involvement in disaster management in the past. (5) The fifth section of the questionnaire explored the demographics of the participants.

All participants provided informed consent.

\section{Data collection}

The questionnaire was initially piloted with ENs in the hospital where the first author is employed. The pilot group was then broadened to also include local experts and staff from other hospitals. Specifically, the pilot group comprised faculty members from King Abdulaziz University, School of Nursing (one male and one female), two members of the management staff (one male and one female) in two of the selected public hospitals, and five nurses (three females and two males) from the ED of the public hospitals selected for the study. It is important to note that the two faculty members were not drawn from the study population. On the contrary, they were experts in the field of nursing research. The aim of using them was to determine the suitability and adequacy of the questionnaire to this study given their experience in this field. On their part, the management staff and ENs were involved to ensure that the participants could understand the questions posed in the survey and that the survey was realistic, feasible and workable to execute within a reasonable time frame. The experts suggested some adjustments in the language of the questionnaire items to make them specific to the field of emergency nursing in Saudi Arabia. The management team and ENs suggested merging some questions to reduce the time needed to complete 
the survey. The revised questionnaire following the pretest took an average of 10-15 min to complete.

The questionnaire was made available in the English language. Forward and backward translations to the Arabic language were conducted by two bilingual ENs during the piloting stage. The importance of having an English language translation was due to the fact that the majority, $53.1 \%$ in 2009 , of nurses working in public hospitals in Saudi Arabia are non-Saudi nationals. ${ }^{23}$ Also, all nurses in the EDs in the hospitals studied were fluent English speakers. The questionnaire was circulated to the managers in each of the selected hospitals by sending the link for the online survey to their individual emails. The hospital managers were asked to distribute the questionnaire among the ENs in their hospitals within a two-week period in September 2014. Participation by respondents was voluntary. To address potential sources of bias, we followed five steps. First, we implemented an appropriate survey structure, which drew on published peer-reviewed questionnaires from similar studies as detailed earlier in this paper. Second, we carefully considered the categorisation (ie, grouping questions thematically into five sections) and ordering of questions with the aim to decrease dropout rates and ensure that the respondents are more truthful with their answers. Third, our data analysis plan informed the crafting of the survey so that the questions were linked to our study objectives. Fourth, the questionnaire was sent out to the whole population of ENs in all public hospitals in Mecca. Fifth, we conducted a pilot using a sample of people from the survey population and additional feedback from local experts to ensure coverage of key topics and that all respondents interpret the question in the same way.

\section{Data analysis}

The survey data collected were analysed quantitatively using the statistics analysis software SPSS (Statistical Package for Social Scientists) V.22. The raw data were downloaded from the Survey Monkey website, checked for missing values and prepared for analysis. Missing values are indicated in parentheses in the results tables when responses to specific items were less than $\mathrm{N}=106$. Missing values related primarily to participant demographics data. The use of an online survey prevented participants from skipping answering questions and, as a result, minimised any missing data to questionnaire items. Descriptive statistics were generated including mean, median, mode, SD, frequency counts and percentages, and crosstabs with the $\chi^{2}$ statistic. Charts and figures were produced to facilitate understanding and comparisons, where appropriate. Statistical significance was defined as $\mathrm{p}<0.05$ for all statistical tests.

\section{RESULTS}

Respondents' demographic characteristics

Table 1 summarises the demographic characteristics of the respondents. The majority were aged between 20

\begin{tabular}{|c|c|c|}
\hline Variable & Frequency & Percentage \\
\hline \multicolumn{3}{|l|}{ Age group $(\mathrm{N}=86)$} \\
\hline 20-30 years & 48 & 55.8 \\
\hline $30-40$ years & 31 & 36.0 \\
\hline $40-50$ years & 4 & 4.7 \\
\hline $50-60$ years & 2 & 2.3 \\
\hline $60+$ years & 1 & 1.2 \\
\hline \multicolumn{3}{|l|}{ Gender } \\
\hline Male & 56 & 52.8 \\
\hline Female & 26 & 24.5 \\
\hline Unspecified & 24 & 22.6 \\
\hline \multicolumn{3}{|c|}{ Current clinical position ( $\mathrm{N}=84)$} \\
\hline Nursing technician & 45 & 42.5 \\
\hline Nursing specialist & 31 & 29.2 \\
\hline Nursing aid & 4 & 3.8 \\
\hline $\begin{array}{l}\text { Other current clinical } \\
\text { position }\end{array}$ & 4 & 3.8 \\
\hline \multicolumn{3}{|c|}{ Years of work in current emergency department $(\mathrm{N}=82)$} \\
\hline $0-5$ & 43 & 52.4 \\
\hline $6-10$ & 27 & 32.9 \\
\hline $11-15$ & 9 & 11.0 \\
\hline $16-20$ & 1 & 1.2 \\
\hline More than 20 & 2 & 2.4 \\
\hline \multicolumn{3}{|c|}{ Years of work in the field of emergency nursing $(\mathrm{N}=82)$} \\
\hline $0-5$ & 46 & 43.4 \\
\hline $6-10$ & 23 & 21.7 \\
\hline $11-15$ & 8 & 7.5 \\
\hline $16-20$ & 2 & 1.9 \\
\hline More than 20 & 3 & 2.8 \\
\hline
\end{tabular}

and 40 years. There were more male $(52.8 \%)$ than female nurses $(24.5 \%)$, although $22.6 \%$ of the respondents declined to specify gender. Over half of the respondents were employed as either nursing technicians or nursing specialists $(42.5 \%$ and $29.2 \%$, respectively, or $53.6 \%$ and $36.9 \%$, respectively, of those who answered this question); few were nursing aides (3.8\%). About $52 \%$ of the respondents reported $0-5$ years' experience in ED, followed by $6-10$ years by $32.9 \%$, and $11.0 \%$ with 11-15 years. Most respondents had worked in the field of emergency nursing for $0-5$ years and $6-10$ years ( $43.4 \%$ and $21.7 \%$, respectively); $12.2 \%$ of the respondents had over 10 years' field experience, of whom $2.8 \%$ of respondents had over 20 years' experience.

\section{ENs' disaster knowledge and awareness}

The reported knowledge of disaster preparedness by ENs was surprisingly very low. Table 2 shows the responses to the 'knowledge assessment test' on topics where there are often misconceptions on the appropriate management of a disaster. Only one in three of the respondents $(34.3 \%)$ correctly responded that most casualties from a disaster arrive at EDs via the Saudi Red Crescent (SRC). SRC is 'a humanitarian society that provides emergency medical services in all regions of the Kingdom of Saudi Arabia. It was founded in 1963'. ${ }^{24}$ 
Table 2 Respondents' knowledge test on disaster misconceptions ( $N=106)$

\begin{tabular}{lll}
\hline Statement & $\begin{array}{l}\text { Frequency who gave the } \\
\text { correct answer }\end{array}$ & $\begin{array}{l}\text { Per cent who gave the } \\
\text { correct answer }\end{array}$ \\
\hline $\begin{array}{l}\text { The majority of casualties from a disaster will arrive at your } \\
\text { emergency department via the Saudi Red Crescent }\end{array}$ & 35 \\
$\begin{array}{l}\text { Disease epidemics are an almost inevitable result of the disruption } \\
\text { and poor health caused by major disasters }\end{array}$ & 33 \\
$\begin{array}{l}\text { The poor are more at risk of death than rich people or the middle } \\
\text { classes during a disaster }\end{array}$ & 30 & 32.0 \\
$\begin{array}{l}\text { Unburied dead bodies will not create a disease epidemic following a } \\
\text { mass gathering disaster }\end{array}$ & 21 & 29.1 \\
$\begin{array}{l}\text { All victims of a CBR incident will have dangerous substances } \\
\text { removed at the scene of an incident prior to their arrival at hospital }\end{array}$ & 17 & 20.6 \\
\hline $\begin{array}{l}\text { CBR, chemical biological-radiological. } \\
\end{array}$ & 16.3
\end{tabular}

A key function of the SRC is to transport patients to EDs and also provide emergency medical services and emergency food supplies in disasters. It also contributes to raising the level of health awareness in the country. Similarly, only $32 \%$ of ENs correctly responded that disease epidemics are an almost inevitable result of the disruption and poor health caused by major disasters; only $29.1 \%$ were mindful that the poor are more at risk of death than rich people or the middle classes during a disaster; only 1 in $5(20.6 \%)$ correctly responded that unburied dead bodies would not create a disease epidemic following an MG disaster; and only 1 in 6 $(16.3 \%)$ responded correctly that all victims of a chemical biological-radiological incident will have dangerous substances removed at the scene of an incident prior to their arrival in hospital. These findings demonstrate a significant deficit in ENs' reported knowledge and awareness to effectively respond to disaster within all of Mecca's public hospitals.

\section{The role of ENs during MGs}

Table 3 presents the ENs' perceptions of their role during the Hajj MG. Respondents perceived their dominant role as providing general assessment and caring for patients $(38 \%)$, followed by triage $(26 \%)$ and resuscitation $(21 \%)$, whereas the respondents gave lower priority to their leadership role $(14 \%)$, and only one

Table 3 ENs' perceptions of their likely role in an MG disaster response during the Hajj pilgrimage $(\mathrm{N}=86)$

\begin{tabular}{lll}
\hline $\begin{array}{l}\text { What is your likely role in a } \\
\text { MG disaster response }\end{array}$ & & \\
during the Hajj? & Frequency & Percentage \\
\hline General assessment and & 33 & 38.4 \\
caring for patients & & \\
Triage & 22 & 25.6 \\
Resuscitation & 18 & 20.9 \\
Leadership & 12 & 14.0 \\
Psychological care & 1 & 1.2 \\
\hline EN, emergency nurse; MG, mass gathering.
\end{tabular}

respondent viewed her role as including providing psychological care $(1 \%)$.

As summarised in table 4, most ENs in Mecca's public hospitals appeared to be confident and knowledgeable about their roles to respond effectively to MG disasters. They reported seeing their main role as providing general assessment and care, with a timely response, including resuscitation, triage and initial consultation, and most reported to communicate well with others during emergency situations; however, fewer ENs saw their role as providing surveillance, prevention, leadership or psychological care in a MG disaster, despite all these roles being described in the standards of care of the hospitals' emergency plans in disaster response.

\section{Disaster education and training}

All respondents indicated that they had received some form of disaster education and training. However, the recency of this training varied substantially, which is an important factor to bear in mind given that the Haij is an annual event in Mecca; only $34 \%$ had attended training in the past $6-12$ months, $23 \%$ attended it in the past 12-24 months, and $43 \%$ attended such training over 2 years ago.

EN respondents indicated that the top three most beneficial types of education and training courses for disaster response preparedness were: (1) hospital education sessions, which were suggested by $43 \%$ of respondents: hospital education sessions involve free courses provided by the Training and Education Centers in Saudi hospitals. (2) The Emergency Management Saudi Course and Workshop, which was suggested by $27 \%$ of respondents: the Saudi Emergency Management course is delivered in Mecca and provides special training for ENs over 2-3 days to help them improve their knowledge of handling emergencies in preparation for the Hajj. (3) Short courses in disaster management, which were suggested by 1 in 10 participants (11\% of respondents). These are courses provided by private organisations.

In contrast, university training in disaster management was perceived as important by only a minority of 
Table 4 Level of understanding of EN role in MG disasters among study participants ( $N=106)(\%)$

\begin{tabular}{|c|c|c|c|c|c|c|}
\hline Role variables & $\begin{array}{l}\text { Strongly } \\
\text { disagree }\end{array}$ & Disagree & Neither & Agree & $\begin{array}{l}\text { Strongly } \\
\text { agree }\end{array}$ & $\begin{array}{l}\text { Total } \\
\text { agree }\end{array}$ \\
\hline $\begin{array}{l}\text { ENs are confident and knowledgeable in effectively } \\
\text { responding to a MG disaster }\end{array}$ & 0.0 & 1.9 & 12.4 & 38.1 & 47.6 & 85.7 \\
\hline ENs are key players in a MG disaster & 0.0 & 5.7 & 11.4 & 38.1 & 44.8 & 82.9 \\
\hline $\begin{array}{l}\text { The main role of ENs during disasters is to provide } \\
\text { general assessment and caring for patients }\end{array}$ & 2.8 & 1.9 & 13.2 & 41.5 & 40.6 & 82.1 \\
\hline $\begin{array}{l}\text { ENs are able to provide timely response to emergency } \\
\text { situations }\end{array}$ & 1.0 & 5.8 & 13.5 & 35.6 & 44.2 & 79.8 \\
\hline $\begin{array}{l}\text { The main role of ENs during disasters is to provide } \\
\text { resuscitation }\end{array}$ & 1.0 & 6.7 & 17.3 & 28.8 & 46.2 & 75.0 \\
\hline $\begin{array}{l}\text { The main role of ENs during disasters is to provide } \\
\text { triage and initial consultation }\end{array}$ & 2.9 & 7.6 & 16.2 & 39.0 & 34.3 & 73.3 \\
\hline $\begin{array}{l}\text { During MG disasters, ENs are responsible for clinical } \\
\text { response }\end{array}$ & 1.0 & 4.8 & 21.0 & 45.7 & 27.6 & 73.3 \\
\hline $\begin{array}{l}\text { ENs can effectively communicate with patients, families } \\
\text { and other clinicians to provide therapies during } \\
\text { emergency situations }\end{array}$ & 2.8 & 5.7 & 19.8 & 34.9 & 36.8 & 71.7 \\
\hline $\begin{array}{l}\text { During MG disasters, ENs are responsible for } \\
\text { surveillance }\end{array}$ & 1.9 & 13.6 & 18.4 & 42.7 & 23.3 & 66.0 \\
\hline $\begin{array}{l}\text { During MG disasters, ENs are responsible for } \\
\text { prevention }\end{array}$ & 2.9 & 13.3 & 20.0 & 40.0 & 23.8 & 63.8 \\
\hline $\begin{array}{l}\text { The main role of ENs during disasters is to act as team } \\
\text { leaders }\end{array}$ & 1.9 & 16.0 & 22.6 & 34.0 & 25.5 & 59.4 \\
\hline $\begin{array}{l}\text { The main role of ENs during disasters is to provide } \\
\text { psychological care }\end{array}$ & 5.7 & 16.2 & 27.6 & 30.5 & 20.0 & 50.5 \\
\hline
\end{tabular}

respondents $(8 \%)$, as was online education about disaster management $(6 \%)$ and self-learning $(3 \%)$.

\section{Level of awareness of the hospital department's major incident plan}

A Major Incident Plan is a contingency plan prepared by the hospitals' departments, which details the critical procedures to be followed in the case of unexpected incidents. Almost half of the ENs $(47.1 \%)$ reported having read their department's Major Incident Plan thoroughly. However, just less than one-quarter of the nurses (23\%) reported that they had only flipped through it, and over one-fifth of them $(21.8 \%)$ had not read it. Moreover, $8 \%$ of them did not know they had one. To be fully prepared for a MG disaster, all ENs are expected to thoroughly read their department's Major Incident Plan. Nonetheless, over half $(52.8 \%)$ of the ENs in Mecca's public hospitals had not thoroughly read the plan, and some of them were not even aware of its existence. This suggests that during a disaster event, over half of the ENs in Mecca's public hospitals may not know or follow the correct standard practices expected in their ED. This could considerably impact on staff's stress levels following a major incident and put patients' safety at risk.

\section{Previous disaster response experience}

Almost all (99\%) of the respondents had previous experience of some type of disaster response. Figure 1 illustrates the frequency and range of previous disaster experiences among study participants; almost 1 in 2
(47\%) had experiences of a fire disaster, 1 in 4 (24\%) of a transport disaster, just over 1 in $5(21.7 \%)$ of a building collapse, 1 in $6(16 \%)$ of a flood, almost 1 in 8 $(12.3 \%)$ of a stampede or an epidemic outbreak, and 1 in $10(9 \%)$ of a biological and chemical disaster.

A $\chi^{2}$ analysis examined the relationships between clinical positions, years in clinical practice and previous disaster response experience and found that specialist nurses are more likely to have previous disaster response experience than other nursing grades; specifically, $71 \%$ of nurse specialists had previous disaster response experience, as compared with nurse aides $(25 \%)$ and nurse technicians $(48.9 \%)$. This difference was statistically significant, $\chi^{2}(3)=8.373, p=0.039$.

\section{DISCUSSION}

Level of awareness and knowledge to respond to MG disaster reported by ENs in public hospitals in Mecca

Disaster knowledge and awareness is a critical component in relation to the preparedness of Saudi nurses for MGs and is a declared priority for the Saudi Arabian Ministry of Health. ${ }^{10} 13$ According to Al-Tawfiq and Memish, ${ }^{10}$ during the Hajj, 24 committees are tasked with the responsibility of promoting awareness and effective communication in preparation for a MG disaster. For example, the Supreme Hajj Committee and the Hajj Preventive Medicine Committee undertake preventive measures prior to, during and after the Hajj. 
Figure 1 Previous disaster response experience of EN respondents ( $\mathrm{N}=86 ; \%)$. EN, emergency nurse.

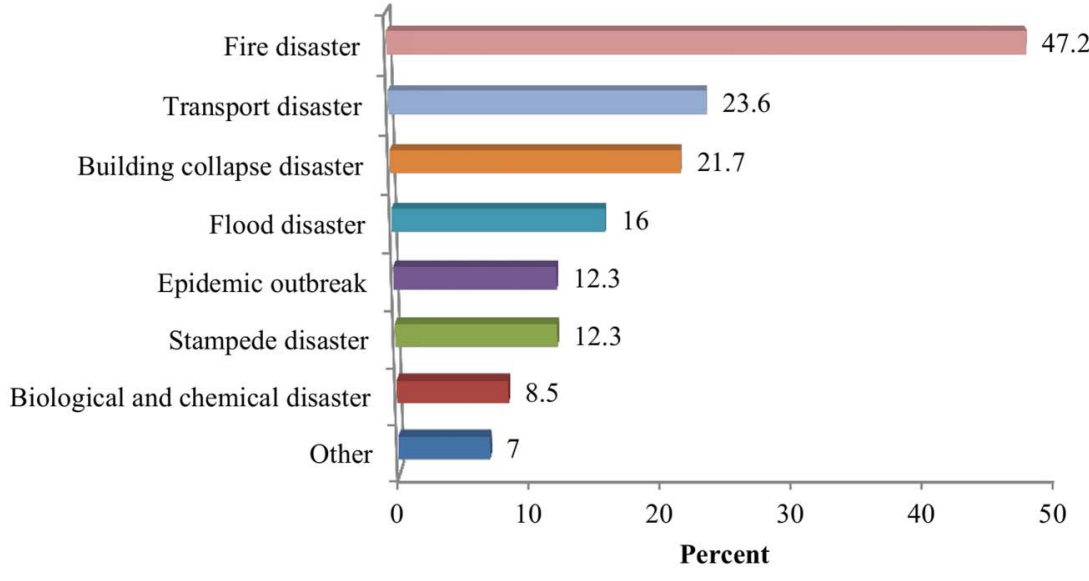

Information regarding estimated imminent disasters or with a high likelihood of occurring is collected and shared by the Saudi Arabian Ministry of Health and the WHO. Despite significant national investment in preparing an extensive communication and knowledge dissemination infrastructure in this field, ENs who participated in this study reported low levels of knowledge on effective disaster response to the Hajj pilgrimage MG. This finding signals the need for substantial improvement in this area, including effective reach-out communication strategies and training targeting nurse practitioners, which currently appear to be substandard.

\section{Disaster education and training}

Education and training on disaster preparedness varied significantly by the clinical post the nurses in our sample held. Involvement in disaster exercises needs to become more standardised and inclusive for all nursing grades in the ED, in particular targeting the less senior roles of nurse technicians and nurse aides.

The Saudi Arabian Ministry of Health has undertaken extensive education and training programmes for ENs and this was somehow reflected in our participants' responses, since almost 9 out of 10 nurses in our sample reported participation in related education and training events.

One of the key developments with regard to education and training for Saudi ENs is the emergence of the specialist field of 'Hajj Medicine'. According to Shafi et al, ${ }^{20}$ this nascent field of applied clinical practice entails management and control of emerging and common health problems during the Hajj. What makes the Hajj so unique for education and training in MGs is that it is the oldest studied MG in the modern world, with reports on the medical management of disease outbreaks published since the 1800 s. $^{25}$ Saudi ENs can extend their 'hands-on' practice experience by reflecting more systematically on this body of codified knowledge and the lessons learnt from many years of effective public health surveillance in the challenging setting of one of the world's largest MGs.

\section{Previous disaster response experiences for ENs}

The finding that $99 \%$ of the respondents had previous experience in relation to disaster response concurs with previous studies, which indicate that the annual undertaking of the Hajj in Saudi Arabia has a significant influence on the level of previous disaster experience among Saudi nurses. In 2008, for instance, the WHO lauded the Saudi public health authorities' exemplary management of communicable diseases in MGs. The $\mathrm{WHO}^{4}$ based their praise on the high level of experience among health workers and their previous undertakings during the Hajj pilgrimage. ${ }^{10} 26$

It is noted that some Saudi ENs lack previous firsthand experience in disaster management. However, it is apparent that the level of exposure of ENs to challenging conditions associated with MGs is considerably higher in Saudi Arabia than in most countries. According to Hammad et al, ${ }^{1}$ South Australian ENs have gencies from prior participation in MG disasters. According to Shafi et al, ${ }^{13}$ Saudi public health officials and health workers, together with policymakers, have seasoned experience and expertise in relation to disaster preparedness and management. The experience stems from the seasonal Hajj occurrence and from other gatherings taking place regularly in the locality.

The majority of study participants reported that they other clinicians during emergency situations. Yet almost one in three ENs reported that they feel they require training to improve these communication skills through, for example, role play, tabletop drills or mentoring.

In terms of training and educational initiatives proposed by the respondents, the majority of ENs in this study find hospital education sessions most beneficial, followed by the Emergency Management Saudi Courses in disaster management. Therefore, these course training formats should be further developed and expanded to ensure that all ENs attend frequently (at least once per year). Second, approximately one-fifth of the ENs are willing to self-learn and use online education about disaster management, which they find beneficial. The limited immediate experience in responding to emercan effectively communicate with patients, families and 
online format is very promising, as it can be deployed to all nursing students with access to the internet (via smartphones, tablets and personal computers). The policymakers and nursing educationists should tap into these avenues for increasing competency among nurses.

Overall, the findings from this study on the roles of the Saudi ENs in Mecca suggest that these nurses are expected to perform a wide range of clinical activities outlined in the Major Incident Plans of local hospitals. Such clinical activities include prevention, surveillance, general assessment and caring of patient, triage, resuscitation, leadership and psychological care. However, judging from the nurses' responses to our questionnaire, ENs appear to put less emphasis on the domains of leadership and psychological care, revealing a rather narrow clinical focus on physical health. They also seem to be geared towards the clinical tasks of acute care provision rather than the more proactive clinical activities of surveillance and prevention.

\section{CONCLUSION}

This study sheds some light to provide a better understanding of the role, though not capacity, that ENs in Mecca are expected to play in disaster preparedness during the Hajj MG. The findings from this study suggest that despite the substantial experience gained through clinical engagement in prior MGs, there is a worrying deficit in knowledge of the Major Incident Plans for ENs working in public hospitals in Mecca. The findings also suggest that ENs seem to be reluctant to undertake a leading role during a disaster response, and to provide preventive and psychological care. Nonetheless, these are essential skills for every individual nurse, who may be called on to make decisions or to support psychologically patients who are affected by stress, panic and/or trauma during the disaster.

The ENs are expected to engage in a wide range of activities geared at assisting members of the public. Hospital, online and university-based training courses and workshops must include a specific focus on disaster response for Hajj and also cover content in the above seemingly neglected areas of clinical practice. The responsibility for this undertaking needs to be overseen by the local and national-level policymakers, with potential involvement of the WHO.

Involvement of ENs in disaster exercises needs to be encouraged and further supported by hospital management and the Ministry of Health, as one in five study participants reported that they had never been involved in disaster exercises, and 4 out of 10 reported having been involved only once.

\section{Limitations and suggestions for future research}

A limitation of this study is the cross-sectional design, which provides a 'snapshot' of ENs' responses at one moment in time. Second, this study included the responses by ENs, but it is also important to survey and interview other clinicians, such as doctors and paramedics, who play an equally crucial role in reducing fatalities at Hajj and at other MG disasters. Finally, the relatively small sample size $(\mathrm{N}=106)$, non-random sample and single setting (Mecca's all four public hospitals), the relatively heterogeneous (three different nursing grades) and rather non-typical group of nurses participating in our study (half of the nurses in our sample being trained abroad), mean the results can only be generalised to other regions of Saudi Arabia and beyond with great caution. A larger national survey of all ENs who have a role in MGs is needed, to gain a broad understanding of their knowledge, experience and training needs for disaster response, so that the Ministry of Health can develop a nationwide policy-driven approach to improve and standardise regular MG and Hajj-specific disaster response nurse training to enhance patient safety. This study did not explore differences in hospital training and exercises across the four hospitals. This is a possibility, and warrants future research, which might explain the reported variation in frequency of disaster education, training and exercise involvement among study participants.

Correction notice This article has been corrected since it was first published. The author name "Kyratsis Yiannis" has been corrected to "Yiannis Kyratsis".

Contributors FA conceived the study and acquired the data. He drafted the work and approves the final version submitted for publication. He agrees to be accountable for all aspects of the work in ensuring that questions related to the accuracy or integrity of any part of the work are appropriately investigated and resolved. YK offered substantial contribution to the design, analysis and interpretation of data for the work. He revised the work critically for important intellectual content. He approves the final version submitted for publication and agrees to be accountable for all aspects of the work in ensuring that questions related to the accuracy or integrity of any part of the work are appropriately investigated and resolved.

Funding The empirical study was supported via a Scholarship Grant awarded to FA by the Saudi Arabian Ministry of Health.

Competing interests FA works as an emergency nurse at the King Fisal Hospital in Mecca, Saudi Arabia. He received a graduate Scholarship Grant from the Saudi Arabian Ministry of Health.

Ethics approval The School of Health Sciences Research Ethics Committee, City, University of London and the Ministry of Health in Saudi Arabia and the R\&D departments of the participating hospitals approved the study.

Provenance and peer review Not commissioned; externally peer reviewed.

Data sharing statement Additional unpublished data from the study are available in the MSc Dissertation document titled: 'Nurse Emergency and Disaster Preparedness during Mass Gatherings: a cross-sectional survey in public hospitals in Mecca, Saudi Arabia' City University London 2015.

Open Access This is an Open Access article distributed in accordance with the Creative Commons Attribution Non Commercial (CC BY-NC 4.0) license, which permits others to distribute, remix, adapt, build upon this work noncommercially, and license their derivative works on different terms, provided the original work is properly cited and the use is non-commercial. See: http:// creativecommons.org/licenses/by-nc/4.0/

\section{REFERENCES}

1. Hammad K, Arbon P, Gebbie K. Emergency nurses and disaster response: an exploration of South Australian emergency nurses' 
knowledge and perceptions of their roles in disaster response. Australas Emerg Nurs J 2011;14:87-94.

2. Magnaye B, Lindsay S, Ann M, et al. The role, preparedness and management of nurses during disasters. Int Sci Res J 2011:3:269-94.

3. Arbon $P$, Bridgewater $F$, Smith $C$. Mass gathering medicine: a predictive model for patient presentation and transport rates. Prehosp Disaster Med 2001;16:150-8.

4. World Health Organization. Communicable disease alert and response for mass gatherings: key considerations. 2008. http://www. who.int/csr/mass_gathering/en/print.html (accessed 15 Jul 2016)

5. Kaji A, Koenig KL, Bey T. Surge capacity for healthcare systems: a conceptual framework. Acad Emerg Med 2006;13:1157-9.

6. De Lorenzo R. Mass gathering medicine: a review. Prehosp Disaster Med 1997;12:68-72.

7. Khan I, McLeod RD. Managing Hajj crowd complexity: superior throughput, satisfaction, health, \& safety. Kuwait Chapter Arabian J Bus Manag Rev 2012;2:45-59.

8. Higgins W, Wainright C, Lu N, et al. Assessing hospital preparedness using an instrument based on the Mass Casualty Disaster Plan Checklist: results of a statewide survey. Am J Infect Control 2004;32:327-32

9. Al-Tawfiq J, Memish Z. Mass gathering medicine: 2014 Hajj and Umra preparation as a leading example. Int $J$ Infect Dis 2014;27:26-31.

10. Chapman $\mathrm{K}$, Arbon P. Are nurses ready? Disaster preparedness in the acute setting. Australas Emerg Nurs J 2008;11.3:135-44.

11. Alexander D. Misconception as a barrier to teaching about disasters. Prehosp Disaster Med 2007;22:95-103.

12. Veenema TG. Expanding educational opportunities in disaster response and emergency preparedness for nurses. Nurs Educ Perspect 2006;27:93-9.

13. Enock K, Jacobs J. The Olympic and Paralympic Games 2012 literature review of the logistical planning and operational challenges for public health. Public Health 2008;122: 1229-38.

14. Conlon L, Wiechula R. Preparing nurses for future disastersthe Sichuan experience. Australas Emerg Nursing J 2011;14: 246-50.

15. Welzel TB, Koenig KL, Bey T, et al. Effect of hospital staff surge capacity on preparedness for a conventional mass casualty event. West J Emerg Med 2010;11:189-96.

16. Rassin M, Avraham M, Nasi-Bashari A, et al. Emergency department staff preparedness for mass casualty events involving children. Disaster Manag Response 2007;5:36-44.

17. Ranse J, Shaban R, Considine J, et al. Disaster content in Australian tertiary postgraduate emergency nursing courses: a survey. Australas Emerg Nurs J 2013;16:58-63

18. Martin J, Ummenhofer W, Manser T, et al. Interprofessional collaboration among nurses and physicians: making a difference in patient outcome. Swiss Med Wkly 2010;140:13062.

19. Ahmed Q, Arabi Y, Memish Z. Health risks at the Hajj. Lancet 2006;367:1008-15.

20. Shafi S, Booy R, Haworth E, et al. Hajj: health lessons for mass gatherings. J Infect Public Health 2008;1:27-32.

21. Twycross A. Research design: qualitative, quantitative and mixed methods approaches. Nurse Res 2004;12:82-3.

22. Bowling A, Ebrahim S. Handbook of health research methods. Maidenhead: Open University Press, 2005.

23. http://www.moh.gov.sa/Pages/Default.aspx (accessed 20 Sep 2016).

24. https://www.srca.org.sa/ (accessed 20 Sep 2016).

25. Memish Z, Stephens GM, Steffen R, et al. Emergence of medicine for mass gatherings: lessons from the Hajj. Lancet Infect Dis 2012;12:56-65.

26. Ahmed Q, Barbeschi M, Memish Z. The quest for public health security at Hajj: the WHO guidelines on communicable disease alert and response during mass gatherings. Travel Med Infect Dis 2009;7:226-30. 